\title{
DISCURSO DE
}

ARTISTAS INDÍGENAS

CONTEMPORÂNEOS

BRASILEIROS: MÚSICA, SOBREVIVÊNCIA, E RESISTÊNCIA LINGUÍSTICA

\author{
Leticia FERREIRA CAMARGO (D) $\boldsymbol{M}$ \\ Universidade Federal de Santa Catarina (UFSC)
}

open access

\section{EDITORES}

- Miguel Oliveira, Jr. (UFAL)

- René Almeida (UFS)

\section{AVALIADORES}

- Vânia Guerra (UFMS)

- Marília Ferreira (UFPA)

DATAS

- Recebido: 31/03/2021

- Aceito: 12/05/2021

- Publicado: 19/06/2021

\section{COMO CITAR}

FERREIRA CAMARGO, Leticia (2021). Discurso de artistas indígenas contemporâneos brasileiros: música, sobrevivência, e resistência linguística. Cadernos de Linguística, v. 2, n. 2, e367.
RESUMO

Este trabalho busca apresentar alguns dos muitos artistas indígenas contemporâneos brasileiros e como suas falas, músicas e lutas diárias se conectam intimamente às discussões sobre políticas linguísticas pró línguas indígenas no Brasil. A partir das falas dos artistas em entrevistas sobre suas motivações e experiências procuro fazer pontes com as discussões acadêmicas e teóricas sobre os processos de apagamento histórico das línguas e modos de ser indígena, e os projetos de resgate e revitalização destes na perspectiva dos estudos de políticas linguísticas. Apresento um breve histórico do embate entre a língua portuguesa e as línguas indígenas no Brasil, e alguns pontos das discussões sobre as relações entre novas tecnologias e povos originários. Os artistas e ativistas têm cada vez mais protagonizado suas lutas em seus próprios termos, e sendo a música uma arte acessível, eles têm levado suas línguas e práticas a espaços de onde eram historicamente excluídos. Considerando a importância do protagonismo dos sujeitos das próprias comunidades envolvidas nos debates e desenvolvimentos de iniciativas de políticas linguísticas, proponho que permaneçamos atentos a essa dimensão artística e seu poder de divulgação e revitalização de línguas indígenas. 


\section{ABSTRACT}

This work seeks to present some of the many contemporary Brazilian indigenous artists and how their speeches, music and daily struggles are intimately connected to discussions about language policies for indigenous languages in Brazil. Based on the speeches of the artists in interviews about their motivations and experiences, I try to build bridges with the academic and theoretical discussions about the processes of historical erasure of languages and ways of being indigenous, and their rescue and revitalization projects from the perspective of language policy studies. I present a brief history of the clash between the Portuguese language and the indigenous languages in Brazil, and some points of the discussions on the relations between new technologies and native peoples. Artists and activists have increasingly carried out their struggles on their own terms, and with music being an accessible art, they have taken their languages and practices to spaces from which they were historically excluded. Considering the importance of the protagonism of the subjects of the communities involved in the debate and development of language policy initiatives, I propose that we remain attentive to this artistic dimension and its power to disseminate and revitalize indigenous languages.

\section{PALAVRAS-CHAVE}

Políticas Linguísticas; Línguas Indígenas;

Artistas Indígenas Brasileiros; Etnomídias.

\section{KEYWORDS}

Language Policies; Indigenous Languages;

Brazilian Indigenous Artists; Ethnomedia. 


\section{INTRODUÇÃO}

Quando os portugueses chegaram acidentalmente ao que chamaram de Terra de Vera Cruz em 1.500, o espaço brasileiro já era ocupado há ao menos 12.000 anos (GUIDON, 1992). Rodrigues (1993) estima, em uma projeção, que o número de línguas faladas no território brasileiro antes de sofrerem fortes efeitos da presença e ação europeia poderia chegar a 1.078 línguas e, em outra, que poderiam ser 1.175 línguas no início da colonização. Já as estimativas de população indígena à época do "achamento" do Brasil variam muito entre autores, metodologias de pesquisa e critérios, com números estimados entre 800 mil e 5 milhões (PAGLIARO; AZEVEDO; SANTOS, 2005). Recentemente, em 2010, de acordo com o Censo do Instituto Brasileiro de Geografia e Estatística (IBGE), o Brasil tinha 896.917 indígenas - aproximadamente 0,4\% da população - de 305 etnias diferentes e 274 línguas indígenas em uso. Mesmo a partir da projeção com menor resultado de Rodrigues (1993), mais de 800 línguas teriam sido perdidas nestes 510 anos, além do extermínio completo de vários povos e quase completo de muitos outros.

Considerando que "o que, de fato, interessa é o desenvolvimento de políticas linguísticas que acarretem na sobrevivência, não apenas de meras materialidades linguísticas, e sim, de discursos indígenas" (MAHER, 2010, p.45) este trabalho objetiva discutir artistas indígenas brasileiros que cantam em língua indígena e/ou sobre questões indígenas. Pesquisei manifestações musicais e em entrevistas, nos quais há evidência de i) formas de resistência, ii) afirmação de identidade e protagonismo de suas próprias narrativas, iii) busca de valorização e revitalização da cultura, iv) esforços de divulgação para e conscientização da população não-indígena. Partindo da compreensão de que a música é muito mais do que apenas entretenimento, como explica Anápuáka Muniz Tupinambá Hã hã hãe, coordenador da Rádio Yandê: "música indígena para nós é mais que divertimento, como muitos acham. É um meio de luta, mobilização, aprendizado, transferência de conhecimento ancestral, não importando o gênero musical usado como elemento de conexão aos prazeres sonoros" (BRUMATTI, 2020), espera-se que as discussões aqui feitas possam contribuir para o debate sobre os discursos indígenas atuais, e participação de jovens indígenas na luta ativa por espaço e reconhecimento frente aos outros $96 \%$ da população brasileira, e inclusão da vozes, narrativas e saberes indígena em espaços de poder:

Não se pode negar a história. O que aconteceu com muitos de nossos antepassados é indigno. O papel de vilão não cabe aos nossos povos e a história precisa recuperar o sentido da participação das populações nativas na formação econômica, cultural, política e até religiosa do país. E a hora e a vez da Palavra ser proferida por aqueles que foram sendo vitimados e excluídos do processo histórico brasileiro (MUNDURUKU, 2018, p.179). 
Os artistas aqui citados são apenas alguns poucos dentre a quantidade cada vez maior de artistas indígenas brasileiros, e de maneira alguma representam a totalidade de artistas indígenas no Brasil, tampouco este trabalho tem pretensão chegar a verdades absolutas ou esgotar os sentidos e as discussões sobre o tema:

i) Brô MC's, o primeiro grupo de rap indígena do Brasil, formado em Dourados (MS) em 2008 por jovens Guarani-Kaiowá com músicas que misturam português e guarani;

ii) Arandu Arakuaa, banda de metal indígena formada em Brasília (DF) em 2008, com músicas em Tupi, Xerente e Xavante;

iii) Oz Guarani (2015) e Wera Trap MC (2011), ambos Guarani Mbya da Terra Indígena Jaraguá em São Paulo (SP) que integravam o extinto Xondaro's (2009) primeiro grupo de rap indígena de São Paulo;

iv) Kaê Guajajara, rapper e escritora Guajajara natural do Maranhão, mora atualmente no Rio de Janeiro (RJ) e integra o coletivo Aldeia Maracanã;

v) Kunumi MC, rapper solo e escritor publicado desde 2014, Guarani da Aldeia Krukutu entre São Bernardo do Campo e São Paulo (SP);

vi) Katú Mirim, rapper desde 2017, Boe-Bororo nascida e criada em Campo Limpo Paulista (SP) faz música em Guarani e em Português, começando a escrever músicas em Bororo;

vii) Djuena Tikuna, cantora, jornalista, pesquisadora da música Tikuna, com músicas em língua Tikuna;

viii) Androyde Sem Par, banda formada no Rio Grande do Norte e radicada em São Paulo, que busca resgatar a memória indígena no RN;

ix) Nory Kayapó, funkeiro Kayapó do Pará, faz funk consciente em língua Kayapó sobre o jeito de viver e amar de seu povo;

x) Brisa Flow, artista Mapuche, filha de imigrantes chilenos. Mineira de Sabará, é MC, rapper, musicista e cantora que discute as vivências da mulher indígena em contextos urbanos em português e espanhol.

Esse trabalho não discutirá os videoclipes dos artistas elencados por acreditar que estes, por si só, merecem discussões complexas e extensas de performatividade, imagem, e indianidade, em trabalhos voltados com atenção a essas dimensões. 


\title{
1. APAGAMENTO HISTÓRICO E O ÍNDIO GENÉRICO
}

O Censo IBGE de 2010 identificou 896.917 pessoas que se declaram ou se consideram indígenas, e destes 63,8\% viviam em áreas rurais, 57,7\% moravam em Terras Indígenas oficialmente reconhecidas, e 36,2\% em áreas urbanas. O mesmo censo identificou 274 línguas indígenas atualmente no Brasil sendo faladas por povos de 305 diferentes etnias. Se ainda sobrevivem os poucos povos e línguas restantes, para Martins, Knapp e Sales isso se deve em muito "aos próprios povos indígenas que, por meio de mecanismos próprios de defesa e resistência, têm tentado sobreviver, mesmo contra o próprio projeto de nação desenhado pelos dominadores ainda nos tempos coloniais" (MARTINS; KNAPP; SALES, 2016, p.308).

A partir do século XVII a língua portuguesa cresceu no Brasil com o Diretório dos Índios de 1758, decreto de Marquês de Pombal que proibia o uso de quaisquer línguas que não o português na escola (MARTINS; KNAPP; SALES, 2016). Assim, foi através de esforços de coerção ideológica e física para que índios abandonassem suas identidades e suas línguas, em prol de um projeto romantizado de nação homogeneizada e monolíngue de Brasil, que as línguas indígenas foram perdendo força e as comunidades linguísticas foram silenciadas (GARGIONI, 2019). Nesse processo, a imposição da língua portuguesa padrão atuou como um elemento de controle, um elemento "civilizador" (SEVERO, 2019b):

\begin{abstract}
foi principalmente devido ao açoite, à ameaça, à intimidação e à depreciação, atos de violência, ora mais, ora menos explícitos, que várias comunidades indígenas brasileiras "optaram por abandonar" suas línguas tradicionais. É, portanto, imperioso, que esse "abandono" seja sempre colocado entre aspas porque uma comunidade de fala não desiste de sua língua livremente. Não é como se ela, racionalmente, pesasse os prós e os contras e, em seguida, tomasse a fria decisão de abandoná-la em favor da língua portuguesa, da língua majoritária (MAHER, 2010, p.34).
\end{abstract}

Os debates sobre a definição do idioma nacional nos anos 1920-1950 se deram em um contexto eugenista e no interior de um dispositivo biopolítico, que são discutidos por Severo (2019b). Esses debates ocorreram centrados no racismo científico, influenciados pela onda eugenista, e transformaram as questões linguísticas em "questões biopolíticas de saúde pública" que ainda têm efeitos atualmente,

\footnotetext{
a racialização linguística, gestada e cristalizada no interior desse dispositivo biopolítico, ainda ressoa em discursos contemporâneos sobre o "português brasileiro", ajudando a reforçar e legitimar o racismo vinculado a uma dada biopolítica brasileira (SEVERO, 2019b, p.141)
}

E é apenas em 1973 com a instituição do Estatuto do Índio (aprovado pela Lei n ${ }^{\circ} 6.001$ ) que ocorre a primeira proposta oficial e institucionalizada de valorização das línguas indígenas, estabelecendo que a alfabetização dos índios seria na língua de sua etnia e também em português "salvaguardado o uso da primeira" (MARTINS; KNAPP; SALES, 2016). Mais adiante, a promulgação da Constituição Brasileira de 1988 ao mesmo tempo oficializa 
a língua portuguesa como idioma oficial e "dá permissão" para o índio ser índio (MAHER, 2016), como explica Maher (2010, p.36):

As políticas linguísticas, implícitas ou explícitas, nunca tiveram como objetivo principal a manipulação, pura e simples, da situação linguística, e sim da identidade étnico-cultural dos grupos indígenas. Isso porque as políticas destinadas a conduzir os povos indígenas a deixarem de falar suas línguas sempre foram instrumentos, não metas.

O apagamento das identidades étnico-culturais indígenas ao longo dos séculos possibilitou o surgimento não apenas da crença de que os índios pertencem apenas ao passado, mas também a noção de um índio genérico, que foi utilizada como estratégia de apagamento e homogeneização dos povos indígenas brasileiros, colocando todos em uma mesma categoria de indianidade romantizada, "refém da ancestralidade", destituindo-os de suas diferenças e singularidades (GARGIONI, 2019; MAHER, 2016a, 2016b; MARTINS; KNAPP, SALES, 2016). Esse apagamento é notado nas falas de diferentes artistas em entrevistas. Bruno Veron, fundador do grupo Brô MCs, fala em entrevista ao Nexo Jornal sobre como a música ajuda a quebrar esses estereótipos:

Para nós é uma honra apresentar a voz indígena no Mato Grosso do Sul, da aldeia para fora, para não-indígenas conhecerem. Mostrar como é a nossa visão da nossa aldeia. Aqui é totalmente diferente, o lado da história é bem outro. Não moramos em ocas, não vivemos nus (MONTESANI, 2017).

Kaê Guajajara relata à Revista TRIP um encontro marcado por essa visão do índio imutável preso ao passado:

Esses dias eu estava na rua, comendo com a minha família, e alguém disse em tom de espanto: 'Nossa, mas uma índia comendo hambúrguer?' As pessoas acreditam que nós somos do passado. Elas não conseguem assimilar o que estamos fazendo aqui e agora (FONSECA, 2020).

Kunumi MC também fala sobre a questão:

Quando comecei, muita gente me criticava, falava que o rap não é da nossa cultura, que a gente estava roubando essa cultura. Hoje mostrei pra muita gente que o rap é uma forma de defesa, de luta, para tentar salvar nosso povo através da escrita, pela música. Muita gente ouviu meu rap e gostou. (MIRIM, 2019)

E por fim, Katú Mirim ao G1:

\begin{abstract}
As pessoas pensam que 'índio' não é uma pessoa em si, mas uma espécie de categoria social, de algo do passado, que vive no meio do mato. Tanto que as pessoas acham que indígena usando celular já não é mais 'índio', só porque usufruirmos de elementos culturais de outros povos nãoindígenas. Isso é um erro, pois além de nos prender no século XVI, ignora todo o histórico de catequizações e os processos de integração social e assimilação cultural, que foram políticas de Estado (LIMA, 2018)
\end{abstract}

Se por um lado esse apagamento histórico das identidades indígenas foi extremamente danoso e prejudicial, por outro, há momentos nos quais alguns indígenas 
optam pelo uso de "nós índios" ou similares nos discursos, como representação da construção de uma aliança política indígena pan-étnica (MAHER, 2016a; GARGIONI, 2019). Essa unificação discursiva dos povos serve para ressaltar interesses em comum, e alcançar maior visibilidade frente ao não-indígenas, considerando que as conquistas de uma aldeia ou etnia ressoam e fortalecem lutas semelhantes de outros, conforme elaborado por Maher: "o branco apagou as diferenças étnicas para apagar o índio da História. Hoje, o índio, por vezes, esconde diferenças étnicas para nela se reinserir" (MAHER, 2016a, p.731). A música, o som, pode ser vista como tendo poder similar de união, "se o som assemelha-se ao espaço, ele reúne igualmente os indivíduos sob sua bandeira. Proferido em comum, ele propicia um sentimento forte de pertença, o de falar uma única voz." (LE BRETON, 2016, p.133, apudFERNANDES, 2018, p.8).

Da mesma maneira, quando um artista indígena se apresenta, principalmente para grandes públicos, está representando em muitas ocasiões mais do que apenas sua etnia ou aldeia. Bruno Veron do Brô Mcs exemplifica isso quando perguntado sobre a experiência do grupo no Festival América do Sul Pantanal (FASP) 2018:

Foi mais uma conquista nossa, digo que subimos mais uma escada. Pra nós, é muito massa estar ali em cima representando o nosso povo Guarani-Kaiowá; não só nosso povo, mas de várias etnias existentes no Brasil [...] Massa levar essas informações que a mídia não mostra, entendeu? Do que acontece realmente com o indígena. Isso que pra nós é importante. Compartilhar a realidade do povo Guarani-Kaiowá e de outros povos. A gente está feliz por isso, bastante emocionado, é um festival grande e a gente nunca pensou em tocar num festival grande assim (MINDÉLO, 2018).

\section{MAIS DO QUE A MATERIALIDADE DA LÍNGUA, DISCURSOS}

Maher afirma que na construção de políticas linguísticas pró-língua minoritária é condição fundamental que "a orquestração de projetos de fortalecimento linguístico seja feita por organizações, instituições e ativistas das próprias comunidades de fala envolvidas" (MAHER, 2010, p.35). A autora identificou que os professores indígenas de sua investigação associavam de maneira muito próxima o fortalecimento de suas línguas e o fortalecimento de suas culturas, ressaltando a importância das crianças na aldeia aprenderem a cantar as músicas tradicionais de seus povos como forma de se aprofundarem na cultura e na visão de mundo e da realidade indígena. Identificando que, para os sujeitos analisados, saber falar uma língua indígena "de fato, implica ser capaz de produzir enunciados culturalmente relevantes" (ibidem, p.44).

A noção de enunciados carregados de cultura são discutidos por Daniel Munduruku, professor e escritor, do povo Munduruku, quando explica que a Memória é um "vínculo com o passado sem abrir mão do que se vive no presente", sendo ela "quem comanda a 
resistência, pois nos lembra que não temos o direito de desistir caso contrário não estaremos fazendo jus ao sacrifício de nossos primeiros pais". É essa Memória que coloca o sujeito "em conexão profunda com o que os nossos povos chamam Tradição". Essa Tradição é passada na aldeia pela Palavra, através dos velhos, sábios e anciões que contam histórias que passam de geração em geração, aprofundando os jovens no contexto e cultura do povo e da aldeia (MUNDURUKU, 2018, p.173).

Essa visão pode ser observada nas falas dos artistas em entrevistas, como Divena Tikuna à Reverb: "a cantoria é nossa identidade. E de certa forma une todos os povos indígenas em uma só canção" (RIBEIRO, 2019). Ao portal online do jornal The Guardian (2020) Zândhio Huku afirma que "você só entende a luta indígena se tiver sua visão de mundo, que entrelaça a natureza e o sagrado"1 (MIRANDA, 2020), e Kunumi Mc para o portal UOL:

\begin{abstract}
A música eu canto somente em guarani. É uma forma de levar um pouco da minha cultura para as pessoas que não conhecem como é a realidade indígena. Porque cada um tem uma cultura e, também, tem sua própria língua. Eu falo guarani, então, acredito muito que, quando eu canto rap em guarani, eu carrego dentro de mim toda minha ancestralidade e junto com eles [os ancestrais] nós fazemos a luta (Kunumi MC sobre seu clipe "Xondaro Ka'aguy Reguá", guerreiro da floresta em português) (DI GIACOMO, 2020).
\end{abstract}

Gargioni (2019) discute a ambivalência da questão da internet nos contextos indígenas, com aqueles que consideram a chegada das tecnologias como uma violência simbólica, apegando-se à ideais de uma indianidade romantizada, e de outro lado, aqueles que compreendem que os indígenas, como qualquer outra pessoa, tem direito às transformações do mundo, às novas tecnologias, e à mudança. Este acesso às novas tecnologias de informação e comunicação facilita que os indígenas possam se inscrever, com sua cultura, língua e narrativas "em tudo aquilo que é veiculado sobre e para eles, em busca de incluí-los em espaços de poder" (GARGIONI, 2019, p.14). São etnomídias, descritas por Severo enquanto

\footnotetext{
uma prática digital de produção e circulação de discursos e vozes indígenas voltados para a ressignificação e promoção dos saberes, cultura e línguas indígenas, feitos pelos próprios indígenas e disponibilizados na rede (SEVERO, 2019a, p.151),
}

e servem para mostrar a realidade e contexto das aldeias e comunidades indígenas, além de denunciar questões voltadas à degradação e preservação do meio ambiente (MUNDURUKU, 2018). Em consonância, Gargioni (2019, p.102) entende como práticas etnomidiáticas

\footnotetext{
as manifestações discursivas contra hegemônicas utilizadas como estratégias de regulação de verdades pela mídia hegemônica, como um campo de exercício de controle e poder e, portanto, como dispositivos de impacto à mudança social e ação política.
}

\footnotetext{
1 "You only understand the Indigenous struggle if you get their worldview, which intertwines nature and the sacred" no original.
} 
Essas mudanças sociais têm cada vez mais afetado a realidade indígena em contextos de fronteiras de aldeias e cidades que vão crescendo e avançando desenfreadamente sobre as terras, visto que "o sistema capitalista tem cercado historicamente - e está cercando cada dia mais- as comunidades ditas tradicionais em minúsculos espaços de terra" (GUEROLA, 2019, p.112). Estes conflitos estão presentes, por exemplo, no seguinte trecho da entrevista de Wera Trap Guarani ao projeto editorial TAB UOL: "venho para a cidade porque quero atingir o mundo através da arte, mas também para conscientizar que eu preciso ter minha vida como indígena também" (MARI, 2019). Em consonância, Djuena Tikuna também fala sobre o papel de sua música e sua arte em sua resistência:

Toda arte indígena é uma forma de resistência. Não tem outro sentido que não seja esse. Pois, há 519 anos, nós resistimos e vamos continuar resistindo. A música que fazemos por si só iá traz essa mensagem, e precisa ser assim mesmo. Todas as conquistas que tivemos foi porque aprendemos a resistir. Assim tem sido ao longo de minha carreira (RIBEIRO, 2019).

Para o vocalista da Arandu Arakuaa, "tendo em vista que a música é um tipo de arte muito acessível, nada mais justo que usá-lo pra dar visibilidade às culturas e lutas dos povos indígenas" (MORO, 2020), e os artistas aqui citados se apropriam das mídias sociais, dessas etnomídias, como espaço de divulgação de seu trabalho e da causa indígena, além de também marcarem presença em plataformas feitas pelas próprias comunidades indígenas, como a Rádio Yandê. Desde 2013 a rádio, que é um ponto de mídia livre, vem difundindo a cultura indígena, na visão da fundadora Aratykyra Tupinambá, enquanto uma etnomídia:

\footnotetext{
uma mídia que não é cópia das outras, mas vira ferramenta de acordo com o povo que dela se apropria a seu modo. Fugindo dos padrões impostos pela mídia não indígena. A Rádio Yandê mostra a importância do protagonismo, independência e autonomia indígena no fomentar do direito à comunicação de todos os povos (AMANTE, 2019b).
}

Em 2019 a rádio realizou o Yby Festival: o Festival de Música Indígena Contemporânea do Brasil, um evento gratuito por meio do qual, durante 3 dias, foi criada uma aldeia multicultural em São Paulo que uniu ancestralidade, tecnologia e arte em suas mais diversas formas, apoiando o protagonismo indígena na sua própria comunicação e história. Katú Mirim foi entrevistada pelo portal Catarinas pouco antes da realização do Festival Yby e foi perguntada sobre o evento:

\footnotetext{
Vai ser um momento muito importante para a gente porque em todo espaço que a gente vai também é uma desconstrução de estereótipos. A gente sabe criar arte, a gente sabe criar um evento. Esses dias um cara falou para mim "nossa, vai ser um programa de índio". E eu falei "sim e isso é muito bom sabia?". Eu ressignifiquei a frase dele e falei que vai ser maravilhoso. Precisa de muito apoio. Por causa do racismo as pessoas desmerecem. Nós vamos provar que sabemos o que estamos fazendo. A gente pode estar sem patrocínio, mas um dia as pessoas irão entender que estamos na produção cultural e existimos em todas as profissões, em todos os recortes e contextos. Eu acredito muito que as pessoas irão começar a patrocinar os eventos. Vai ser um evento muito importante para a comunidade indígena, para os artistas indígenas. Ser artista no Brasil é difícil, agora você imagina para um artista indígena. O tempo todo eu tenho que falar que eu faço rap, que eu sei rimar. Então vai ser um evento importante para todo mundo (AMANTE, 2019a).
} 
Também em 2019 foi realizada a primeira edição do Festival Intergalático dos Povos Originários, realizado na terra da tribo da Reserva Indígena Pataxó Porto do Boi em Caraíva, na Bahia. Reunindo povos de diversas etnias indígenas e quilombolas durante 4 dias atuando no resgate e expansão das culturas e saberes dos povos originários, em um espaço que está desde o fim de 2018 em um processo ativo de revitalização -o projeto De Volta ao Porto do Boi procura "restabelecer, promover e sustentar valores tradicionais da tribo Pataxó do Porto do Boi":

Envoltos em um mundo cada vez mais complexo, com número de desafios que só cresce, variando entre problemas ambientais até densificação urbana, nós consideramos que olhando para trás nas nossas raízes nós podemos achar ferramentas de empoderamento para nos guiar para um futuro de soluções (PORTO DO BOI).

\section{ARTISTAS INDÍGENAS CONTEMPORÂNEOS BRASILEIROS}

\subsection{BRÔ MC’'S}

Pioneiros e inspiração para toda uma geração de novos artistas indígenas contemporâneos, o primeiro grupo de rap indígena do Brasil é Brô MC's, cujos integrantes começaram a cantar e se apresentar em 2008 em Dourados (MS), cidade que é palco de disputa pelo território ancestral dos guarani-kaiowá. Os integrantes são Guarani-Kaiowá, vivem na Aldeia Jaguapirú Bororó e suas rimas mesclam guarani e português visando "amplificar suas músicas por meio das redes sociais e aproximar os não-índios para assuntos como lutas, anseios, conquistas e vitórias dos povos indígenas de todo o Brasil" (descrição do grupo em sua página no Facebook). Alcançaram visibilidade em muitas frentes diferentes, se apresentaram na posse da presidente Dilma (2010), no Fórum Social Temático em São Leopoldo (RS) em 2012, seus clipes marcaram presença na antiga MTV, abriram show de Milton Nascimento em 2012, e também estiveram no programa TV XUXA (2012). A canção "Terra Vermelha" compõe a trilha sonora de "Em Busca da Terra Sem Males", curta-metragem de Anna Azevedo apresentado no Festival Internacional de Berlim de 2017, e a história do grupo também serviu de inspiração para a minissérie Guateka (2019), ficção baseada em fatos reais e no cotidiano da aldeia que apresenta à população não indígena a cultura Guarani-Kaiowá em 5 episódios. Fundador do grupo, Clemerson Veron fala sobre o grupo enquanto inspiração e esperança para outros:

\footnotetext{
esses tempos a gente tava lá pra baixo na aldeia, aí molecada chegou pra gente e falou: "a gente tá fazendo um grupo aí.. depois vem dá uma ideia pra nós". Depois também encontrei uma mulher na aty guasu jovem e ela falou que ia começar a cantar rap também. Através disso o Bro MC's ganha mais esperança porque o Bro MC's é a esperança porque a gente ajuda outros indígenas a ficarem fortes! (Clemerson, entrevista Bro MC’s, 2014 ) (OLIVEIRA, 2016).
} 
Bruno Veron, também fundador do grupo, em entrevista para a série "519 anos de resistência: um retrato do Brasil indígena" da Rádio Globo reforça a intenção do grupo de acabar com o estereótipo do índio romantizado do passado, em um esforço de conscientização da população não-indígena:

A principal mensagem que a gente pretende levar é que o indígena de hoje em dia é modernizado. Não é mais aquele indígena que vive só de tanguinha e de flechinha [...] É a mesma coisa o brasileiro, que vai para a Europa e para os Estados Unidos e nunca deixa de ser brasileiro. O rap é só uma ferramenta para a gente se comunicar. É a mesma coisa que você ter um celular. O celular não é do brasileiro, ele vem de fora. E você tem o celular, mas nunca deixa de ser brasileiro. É uma ferramenta que você usa" (Bruno Veron, Reverb, 2019).

\subsection{ARANDU ARAKUAA}

Arandu Arakuaa, que em Tupi-guarani significa "saber dos ciclos dos céus" ou "sabedoria do cosmos", é uma banda de metal indígena, formada em 2008 em Brasília. Zândhio Huku é vocalista, guitarrista e fundador da banda. É descendente de uma avó indígena e cresceu perto de aldeias em contato constante com as comunidades indígenas Xerente e Krahô no Tocantins. A banda enfrenta preconceitos em muitas frentes: a composição do grupo é pouco comum no cenário do metal, com uma vocalista mulher, um vocalista nortista descendente de indígenas, um baterista negro, e integrantes filhos de nordestinos. Outro preconceito que sofrem é pelas línguas em que as músicas são compostas, pois as letras das canções são em Tupi Antigo, Tupi-guarani, Xerente, Xavante, e português. Zândhio inclusive explica à BBC (2016) a dificuldade de disponibilizar as traduções das letras da banda em sites especializados, que não reconhecem as traduções por entender as línguas indígenas como não existentes, mesmo quando ele tenta inseri-las pessoalmente. Por isso, legendaram todos os vídeos da banda no Youtube e enviam um arquivo de todas as letras e traduções aos fãs que entram em contato com dificuldade de encontrá-las na internet.

Zândhio também é professor. Já lecionou História e atua como pedagogo nos anos iniciais do ensino fundamental em um esforço de divulgação das causas indígenas e conscientização da população não indígena:

\footnotetext{
O compromisso com os povos originários que sempre fez parte da minha vida diária, na minha atuação na educação não é diferente. Sempre que surge uma brecha no currículo para trabalhar com algo relacionados aos povos originários tento me empenhar ao máximo para que meus alunos possam ter acesso a essas informações (MORO, 2020).
}

A banda lançou 4 singles em 2020, mas o primeiro álbum é de Kó Yby Oré 2013, composto de 13 faixas, todas em Tupi Antigo. O segundo álbum, Wdê Nnãkrda (tronco de árvore no idioma Akwẽ Xerente) de 2015 tem 5 músicas em Akwẽ Xerente, 3 em Tupiguarani, 2 em Xavante e 1 em português. O terceiro álbum é MRÃ WAZE ('Respeito a 
Natureza' em Xerente) de 2018 e tem músicas nas mesmas línguas do anterior. Em entrevista ao portal UOL, Zândhio explica a escolha linguística do primeiro álbum:

A escolha do tupi para o primeiro álbum tem mais a ver com sua importância na formação da nação brasileira, mas poderia ter sido outra língua indígena do Brasil; a musicalidade e divulgar as culturas indígenas do país são o mais importante. [...] Material de estudo (sobre tupi) ainda é difícil, só há uma gramática no mercado. Os povos indígenas têm a cultura da língua oral, e são poucos os trabalhos relacionados às línguas indígenas, que geralmente são feitos não por índios, mas por missionários religiosos. O tupi é o caso mais clássico (DEHÓ, 2014).

\subsection{OZ GUARANI E WERA TRAP MC}

Wera e Xondaro integravam o Xondaro MC's formado em 2009, por jovens lideranças Guarani Mbya da aldeia Teoka Pyal do Pico do Jaraguá em São Paulo (SP). A Terra Indígena Jaraguá é a menor terra indígena do Brasil, com uma área demarcada em 1987 de 1,7 hectares (FERNANDES, 2018). Em 2011 Wera iniciou carreira solo, já abriu show para Criolo e também levou o rap indígena brasileiro para Frankfurt na Alemanha em 2018, tem músicas em português e em guarani. Wera tem se dedicado a finalizar a construção de um estúdio de gravação na aldeia: "a ideia é trazer jovens de outras tribos aqui para incentivar o trabalho com música e fazer essa troca" (Wera, G1 SP, 2019). Em entrevista à Vice, Xondaro fala sobre a importância da voz indígena no rap que pode ser vista como reafirmação de sua indianidade:

\footnotetext{
A gente não tem uma produção grande, somos independentes e corremos atrás das coisas. Mas a vida indígena é conhecida pela sua capacidade de luta e resistência. Foi através da arte que a gente conseguiu enxergar outro caminho. A partir disso percebemos que estávamos representando a nossa comunidade e as nossas crianças através da música. A nossa voz no rap é muito importante para que a sociedade possa entender o que a gente está passando (BARBA, 2017).
}

Xondaro fundou e integra o grupo Oz Guarani, com músicas em português e em guarani, que começou em 2015 como forma de resistência:

\footnotetext{
A gente começou há dois anos durante uma ordem de reintegração de posse solicitada judicialmente. Foi durante este tempo, indo em protestos e assembleias, que me aproximei do Mano Glowers e do Vlad Macena. Decidimos escrever uma carta para mostrar para a sociedade o que estávamos passando naquele momento. Foi aqui na aldeia Tekoa Pyau que a gente começou a rabiscar essa carta que futuramente se transformaria na primeira letra de música do grupo (ibidem).
}

A aldeia foi fundada pela avó de Wera, abrigando hoje 700 índios, e está cada vez mais ameaçada pelo crescimento de São Paulo. "Se eu perder essa terra, eu não consigo me ver em outro lugar" Wera afirma em entrevista à Ponte Jornalismo (2020). No início de 2020 os Guarani Mbya do Pico do Jaraguá entraram em embate com uma construtora que ameaça derrubar centenas de árvores no território para construção de um empreendimento imobiliário a cerca de cem metros da aldeia. Em abril de 2020 uma decisão da justiça federal de São Paulo proibiu a construtora de "realizar quaisquer atividades de manejo 
ambiental ou qualquer obra para implantação do empreendimento imobiliário na área" (SÃO PAULO, Justiça Federal da $3^{a}$ região). A música e clipe de "Guardiões da Floresta" de Wera conta sobre esse embate.

Em entrevista ao G1 SP, Xondaro fala sobre o receio inicial dos próprios indígenas que o contato com o rap pudesse influenciar negativamente:

Eu tive bastante dificuldade no começo quando o rap indígena surgiu na aldeia. A gente passou por preconceito até mesmo dos nossos parentes, que diziam que a gente não podia cantar o rap porque eles tinha medo que a gente esquecesse a nossa língua, a nossa cultura, a nossa raiz, por ter contato com o não-indígena. Mas aí, com o passar do tempo, eles foram vendo que o rap de alguma forma estava dando visibilidade para a aldeia, então hoje o rap é respeitado (VIEIRA, 2019).

O rapperalém de falar sobre questões linguísticas, explica questões culturais indígenas e alguns dos problemas que a comunidade vem enfrentando. No entender de Fernandes (2018), a arte dele representa o fato de:

\footnotetext{
"...a gente não vê na televisão, a mídia mostrando jovens, é Guarani Kaiwoa de Mato Grosso do Sul sendo mortos por fazendeiros. Eles não mostram a invasão dos fazendero nas aldeias não mostra o conflito né? Então algumas partes das nossas letra é bem pesada que fala exatamente isso. Então a gente usa a língua portuguesa pra mandar essa mensagem pra população não indígena. E tem grande parte que a gente faz em guarani, e que é mais pro jovens, que é mais pras mulheres, e pras pessoas mais antigas né? A gente é, tenta, de alguma forma, levantar a pessoa que tá triste. E a pessoa, muitos dos jovens já tiveram depressão nas aldeias, não só aqui como em toda, toda aldeia né então eu também já tive, já passei por isso, então eu consegui vencer isso, eu sou muito grato pelos amigos que eu tinha, eles de alguma forma nunca me deixaram só, sempre acreditaram no meu trabalho, eles diziam eu começava a brincar, escrevia uma letra rimava algumas coisas, as palavras já vinham, você tem que seguir esse caminho mesmo porque a sua palavra tem poder, o seu jeito de falar você conquista as pessoas. Então em todo lugar que eu ia eu notava isso, eu puxava a multidão comigo então exatamente por conta disso eu um dia decidi fazer, me envolver, quer dizer, é cada vez mais fundo nessa luta dos mais antigos né?..." (Mc Xondaro entrevista concedida a Lais Silvestre Fernandes. São Paulo, 4 novembro 2018). (FERNANDES, 2018)
}

\subsection{KAÊ GUAJAJARA}

Kaê Guajajara nasceu em uma terra não demarcada em Mirinzal, na parte amazônica do Maranhão, "lá foi o último lugar onde a minha família parou depois muitos processos de violência, que ainda enfrentam principalmente por parte dos madeireiros" (FONSECA, 2020), e por causa de conflitos com madeireiros a família de Kaê precisou se mudar para o Rio de Janeiro. Faz parte do coletivo indígena que ocupa atualmente a Aldeia Maracanã, erguida por diferentes etnias no terreno que antes abrigava o Museu do Índio. Autora do livro Descomplicando com Kaê Guajajara - O que você precisa saber sobre os povos originários e como ajudar na luta antirracista, produzido por representantes de 12 diferentes etnias indígenas brasileiras e voltado à população não-indígena:

A maior importância é colocar uma ferrameta para a educação antirracista dentro das instituições. A sociedade cresceu aprendendo várias inverdades sobre a gente. E agora temos que aprender a lidar com a consequência dessa ignorância e ensinar as pessoas a nos tratar como seres humanos (BRITO, 2020). 
Kaê faz rap e funk em português, mesclando elementos de sua língua Ze'egete sobre suas vivências e violências sofridas enquanto mulher indígena nos contextos urbanos, e também músicas voltadas a outros indígenas, focadas no acolhimento: "Eu não posso parar a minha vida para educar o branco. Então tento manter um equilíbrio entre oferecer amor e clamar por justiça" (Kaê Guajajara, Revista TRIP, 2020). Em outra entrevista, ao The Guardian, Kaê encapsula sua afirmação de identidade e resistência: "tenho medo de me embranquecer. Tenho que ter cuidado para manter minhas raízes e cumprir minha missão: infiltrar estruturas de poder que dizem que os povos indígenas não existem mais" (MIRANDA, 2020). ${ }^{2}$

\title{
3.5. KUNUMI MC
}

Kunumi Mc mora na aldeia Krukutu, localizada entre as cidades de São Bernardo do Campo e São Paulo, é rapper e escritor, e conseguiu muita visibilidade, na abertura da Copa do Mundo de 2014, ao protestar, erguendo uma faixa em que estava escrita a palavra "DEMARCAÇÃO". Na ocasião, foi convidado a soltar uma pomba pela paz no estádio. O protesto não apareceu na transmissão, mas repercutiu no mundo:

\footnotetext{
Muita gente me viu, muita gente. Quando saí do campo os jogadores pegaram a faixa e eu deixei, fui ver o jogo lá em cima e voltamos para casa. Contei pro meu pai, que achou estranho, disse que não viu nada, só o menino soltando a pomba da paz. A TV não mostrou o protesto que eu fiz. No outro dia vieram europeus, muita gente de fora do Brasil para saber o que é demarcação e porque eu fiz aquilo. Vieram pra me conhecer, saber quem eu sou e para que servia aquela faixa. No outro dia a gente viu a foto, repercutiu muito (MIRIM, 2019).
}

No mesmo ano, Kunumi, que é filho de Olívio Jekupé, o primeiro escritor indígena do Brasil, se tornou o mais jovem escritor indígena do país, publicando junto ao irmão Tupã Mirim o livro "Contos dos curumins guarani" e também sozinho o livro infantil "Kunumi Guarani”. Inspirado pelos grupos Brô MCs e Oz Guarani, tem dois discos gravados "My Blood is Red" (2016) e "Todo Dia é Dia de Índio" (2018):

\begin{abstract}
Eu escolhi a literatura para minha vida. Um dia eu estava escrevendo, lendo os livros do meu pai e eu gostei muito - são poesias, e foi ali que tentei escrever poesia e transformar em música. Eu não sabia que aquilo era rap, mas já tinha ouvido os Brô MC's, que é o primeiro grupo de rap indígena. Eu vi que eram letras de luta, muitas rimas, e eu percebi que tinha feito um rap. Escolhi essa literatura depois da copa do mundo. Quando comecei a cantar rap eu não sabia muito de qual tema falar. Só que eu sempre me lembrava do protesto que fiz na época na Copa do Mundo e me dava inspiração. Então, escrevo só sobre o tema, questão indígena, saúde, a importância de demarcar a terra indígena (ibidem).
\end{abstract}

O rapperfalou à UOL sobre a imagem preconceituosa e estereotipada do índio genérico:

2 "I am afraid of whitening myself. I have to be careful to keep my roots and accomplish my mission: infiltrate power structures that say Indigenous peoples no longer exist" no original. 
E a imagem que o homem branco tem é um preconceito, que quando um índio canta rap ou usa alguma arte isso é uma perda de cultura. Mas não é. Quando eu uso meu rap e minha literatura nativa eu uso para defender o meu povo. Então, o indígena, na visão do branco, já é muito ruim, mas quando se fala de um indígena artista é pior ainda. Mas o importante é a gente fazer o que a gente gosta e o que é preciso. Porque o homem branco desde 1500 roubou muita coisa da gente. O verdadeiro golpe aconteceu em 1500 roubando as nossas terras. Depois deram facões pra gente, deram muita coisa, mas sempre querendo algo em troca. Foi ali que a modernidade começou para o indígena. E até hoje a gente usa camisa, mas usamos porque é uma necessidade, assim como usamos o celular e as redes sociais para nos comunicar com os parentes e contar o que acontece nas aldeias indígenas. Porque eles pensam que os indígenas estão congelados no tempo, estão isolados na mata, tranquilos. A gente vive tranquilo mesmo, mas também passamos dificuldade. Somos ameaçados diariamente pelos governantes que não querem dar as terras pra gente, não demarcando. Quando se fala de um índio, ninguém tem noção de como é a realidade de um indígena, né? Só quem convive com um indígena sabe como é. Não vamos virar branco só porque estamos usando o rap e a literatura nativa (DI GIACOMO, 2020).

\subsection{KATÚ MIRIM}

Katú Mirim é rapper da etnia Boe-Bororo, nasceu na periferia, em Campo Limpo Paulista (SP), foi adotada aos 11 meses de idade por um casal hétero, branco e evangélico. Só entrou em contato com seu pai biológico, do povo Bororo, aos 13 anos, e a partir desse momento começou a se identificar como descendente indígena. Com quase 19 anos, começou a se dizer indígena e enfrentou questionamentos na cidade por ter nascido na periferia e não na aldeia: "Eu sei disso através da memória ancestral, que eu parei na periferia por causa de um genocídio. A periferia é quilombo, é aldeia" (AMANTE, 2019a). Em sua longa e complicada busca pela retomada de sua identidade, Katú entrou em contato com a aldeia do Jaraguá (SP) na Terra Indígena Itakupé, onde foi batizada de Katú e começou a aprender a língua e a cultura guarani. Algum tempo depois desse contato, foi à aldeia Meruri no Mato Grosso, onde ouviu do cacique José Mário que "Bororo é aquele que mantém a sua cultura, é aquele que quer manter viva sua cultura, sua memória e identidade. Você é de tão longe e faz tanto tempo, mas você é bororo, eu te reconheço como bororo" (ibidem). Ainda sobre a experiência na aldeia, Katú diz "quando eu saí da aldeia eu saí preenchida não somente das histórias orais, mas eu saí cheia de livros da língua. E aquele vazio acabou" (ibid).

\footnotetext{
Hoje eu me sinto privilegiada por saber quem é o meu povo e ter sido acolhida por essas três famílias, a que me adotou com 11 meses, e depois pelos Guarani e Bororo. Hoje, falo que sou Guarani, Bororo, Tupinambá, eu sou todos os povos. Porque se for pegar quem está em mim na verdade são todos os povos. Na verdade quando eu vou lutar eu não luto pelo meu povo que tem a terra homologada e demarcada, eu luto por todos, pela liberdade de todos os povos. Uso o rap para falar disso, assim como a internet, a performance e as artes cênicas, tudo o que eu puder usar para falar disso" (ibid).
}

Katú lançou seu primeiro EP "Nós" em 2020, e suas músicas são em guarani e em português, além de estar estudando e começando a compor em Bororo. Sobre algumas letras de suas músicas estarem em guarani, ela explica:

É o nhanderekó (modo de vida). Eu coloco muito a língua Guarani. Sou chamada de xondaria (guerreira), e uso aguyjevete (gratidão). Agora comecei a escrever músicas na minha língua. Às vezes, misturo as duas línguas e acho isso bom. Para uma pessoa que estava vazia de memórias, agora estou transbordando (AMANTE, ,2019a) 
Em 2018 a rapper lançou a campanha \#ÍndioNãoÉFantasia para questionar a representação estereotipada indígena e o racismo envolvido no uso de fantasias de índio como cocares, pinturas corporais e penas:

\begin{abstract}
Eu não vim dizer o que as pessoas podem e não podem fazer, vim pedir para elas refletirem sobre nossa existência. Eu tenho muitos vídeos didáticos, eu canto, mas nunca me escutaram. No momento que eu faço um vídeo curto pedindo respeito, eles me massacram. Eu peço que olhem para os povos indígenas, nos respeitem, lutem conosco [...] Acham que é homenagem, porque é 'exótico', 'algo natural do Brasil', que faz parte da cultura brasileira... mas se você pergunta a qual povo aquela pessoa está homenageando ao se fantasiar, ela não saberá responder, até porque dificilmente as pessoas conhecem nossa pluralidade étnica (LIMA 2018).
\end{abstract}

Antes de alcançar visibilidade com seu trabalho musical a rapper era vlogger, com um canal no YouTube com 9 vídeos sobre diferentes questões indígenas, e seu canal é analisado junto ao de outros 3 vloggers indígenas na tese de doutorado de Gargioni (2019).

Ademais, Katú, que é bissexual, também fundou o Coletivo Tibira (@indigenaslgbt no Instagram), um espaço de acolhimento e divulgação de indígenas LGBT ao redor do mundo. O nome é em homenagem à Tibira do Maranhão, indígena tupinambá executado no século XVII pelos colonizadores franceses por sodomia, considerado o primeiro caso documentado de execução por homossexualidade no Brasil, ou em termos modernos, homofobia (MOTT, 1993).

\title{
3.7. DJUENA TIKUNA
}

Djuena Tikuna nasceu na aldeia Umariaçu II, na região do Alto Solimões no Amazonas, próxima das fronteiras de Peru e Colômbia. É da etnia Tikuna, a nação indígena mais numerosa do país. Cantora e pesquisadora da musicalidade do povo Tikuna, influenciada por sua família - sua avó materna fazia canções de improviso, e sua mãe é cantora do tradicional grupo Wotchimaücü, lançou em 2017 seu primeiro álbum "Tchautchiüãne" (Minha Aldeia) com todas as músicas na língua Tikuna. Também produziu o documentário "Wiyaegü: A música Tikuna". No lançamento de seu álbum, foi a primeira mulher indígena a se apresentar no Teatro Amazonas nos seus 121 anos de existência:

\footnotetext{
- Teatro Amazonas, construído no apogeu da Borracha, período de maior destruição física e cultural do povo Tikuna, teve que receber, pela primeira vez, em mais de 120 anos de história, um show de uma artista indígena. Lotamos o Teatro com a participação de artistas indígenas representando várias regiões do Amazonas, com direito a fala de lideranças do movimento indígena, quebrando o protocolo da casa (RIBEIRO, 2019).
}

Participou do projeto Sonora Brasil que objetiva levar a música indígena em turnê por todo o Brasil e para fora dos grandes centros urbanos, e em 2018 foi indicada ao Indigenous Music Awards, que acontece anualmente no Canadá na categoria de Melhor Artista Internacional, sendo a primeira artista da Amazônia Brasileira indicada ao prêmio. Também é idealizadora da $1^{a}$ mostra de música indígena do Amazonas - WIYAE. 
Seu site é ao mesmo tempo de divulgação de sua música, de notícias indígenas e de outros projetos, como o Mosaico da Música Indígena,

uma iniciativa independente de registrar, os diversos artistas dos mais de 305 povos indígenas vivendo no Brasil, com o objetivo de montar um grande portfólio de artistas indígenas, com o nome e contato destes, contribuindo com a divulgação dos seus trabalhos e facilitando o processo de contratação para apresentações culturais, shows, vivências, entre outros [...] A cultura está ligada a nossa essência e integrada ao Território, a Saúde, a Educação e por todos as nossas outras reivindicações. Falar de cultura é importante, pois destaca quem somos e quem defendemos ser. Que nossos cantos ecoem pelo mundo, levando a voz de nossa resistência (Release do site Djuena Tikuna).

É também a primeira jornalista indígena formada no Amazonas e atua como palestrante sobre

musicalidade indígena e de todo esse universo cultural produzido pelos povos originários, através de sua contribuição pessoal para a quebra de paradigmas, estereótipos e pelo fim do preconceito contra os povos indígenas e comunidades tradicionais (Release do site Djuena Tikuna).

Ganhou visibilidade também ao participar de um clipe parte da campanha de Demarcação de Terras Indígenas produzido pelo Greenpeace e Articulação dos Povos Indígenas do Brasil (APIB) junto a artistas como Marlui Miranda, Gilberto Gil, Ney Matogrosso e Maria Bethânia.

\subsection{ANDROYDE SEM PAR}

Banda fundada em Natal (RN) em 2013, e radicada em São Paulo, com dois álbuns lançados. "GRAVE" em 2013, e "RUYNAS" em 2019, que em clima de MPB aborda complexidades indígenas de ancestralidade e identificação, migração nordestina, e também questões LGBTQI. A banda fala muito sobre a excepcionalidade indígena brasileira no Rio Grande do Norte, único estado sem nenhuma terra demarcada, e também o estado com a menor autodeclaração indígena: "será possível reivindicar a demarcação de terras se não demarcarmos primeiro nossos imaginários com herança indígena?”3 (MIRANDA, 2020) questiona Juão Nyn, vocalista da banda. Em entrevista à O inimigo - Medium, Juão explica sobre os esforços da banda, o cenário no RN e também a escolha pela adoção do y ao invés do i enquanto resistência linguística:

O RN tem muyto yndyo. [...] O que não tem são muytos yndygenas polytyzados e conscyentes. Porque nosso estado é pouco polytyzado e conscyente. Então exyste um movymento de ressurgencya yndygena desde 2005 que acontece por autodeclaração coletyva em varyas comunydades como Katu, Amarelão, Tapará. Mas exystem muytos yndygenas urbanos que não se reconhecem como yndygenas. As pessoas com essa cultura ou fenotypo que me procuram, falo que precysamos parar de pensar somente em ancestralydade e sym em ydentydade

3 "Is it possible to claim for land demarcation if we don't first demarcate our imaginaries with Indigenous heritage?" no original. 
yndygena contemporânea. A mestyçagem não pode vyr pra apagar ydentydades. Ysso fortalece a ydentydsde latyno amerycana e dyluy muytos preconceytos. Então se não eh branco e não é preto, é o que? Pardo? Pardo não exyste. Não exyste o movymento pardo. Pardo foy a prymeyra coysa que dysseram sobre nós e foy registrada no prymeyro documento lyteraryo brasyleyro que é a carta de Pero Vaz de Camynha. "E eram todos pardos, todos nus, sem coisa alguma que lhes cobrisse suas vergonhas". A questão é que dyante da colonyzação o RN quer ser o que não é. A ydentydade foy soterrada. Somos o melhor projeto da colonyzação. Não sabemos quem somos. É o nynguenysmo de Eduardo Galeano. Então sabendo da hystorya da mynha famylya, do rosto do meu pay e da mynha mãe, de como me xyngavam na ynfancya. De como chamam meu pay de "bolyvya", sabendo a hystorya do RN, a hystorya do Brasyl, confirmado pelas pessoas mays velhas de ambos os lados dq mynha famylya, meus olhos, mynha cultura ynteryor que não bate com essa hollywoodyzada, eu entendo que não sou branco, mesmo com pele clara. Entendo que nunca serey Leonardo di Capryo como querya ser quando pequeno. Entendo que não somos todos yguays. E que os colonyzadores fyzeram móveis e monumentos com mynha árvore genealógyca. As pessoas confundem yndygena com aldeyado. Então só é preto quem vyve em quylombo. Eu era chamado de "yndyo vyado" quando menor. Crescy, mygrey e fyz a questão yndygena não ser algo dystancyada. Não é só anslcestralydade. O RN É o estado com menor auto declaração yndygena pelo YBGE não por não ter yndyo. Mas porque a proybyção de falar a lyngua e as mygrações forçadas foram dyluyndo os povos. Mynha famylya potyguara por parte de pay veyo do Ceará. É ysso que tem me mantydo vyvo e em movymento, esse escavamento. Que poluy tudo que tenho feyto. Por isso o y. Vogal sagrada Guarany. Como demarcação lyngystyca yndygena na fala portuguesa. Porque nem o yngles, nem o espanhol, nem o português são da ameryca (MORAIS, 2019).

\subsection{NORY KAYAPÓ}

Nory Kayapó é funkeiro, mora na Terra Indígena no município de Novo Progresso no Pará, e faz funk em língua Kayapó: "quero falar sobre diversão na minha língua, quero alcançar mais pessoas. O funk mudou a minha vida, conseguir cantar sobre isso é muito gratificante" (ANDRADE, 2019). É conhecido por seu álbum "Hina Hina" e descreve seu funk consciente como "Mē õ nire jã né ba imãkinh" (esta indiazinha que eu amo). Seu canal no Youtube tem mais de 20 mil inscritos, e surgiu depois de escutar uma playlist de funk, quando começou a escrever músicas em língua indígena para que os indígenas se sentissem representados na sua arte: "minha ideia desde o começo foi me expressar e cantar sobre o que eu queria em um ritmo que as pessoas não imaginam que pode ser cantado por um índio" (ANDRADE, 2019).

\subsection{BRISA FLOW}

Brisa é filha de imigrantes chilenos, nasceu e cresceu em Minas Gerais, é etnia Mapuche. É cantora, musicista, MC, arte-educadora. Sobre seu primeiro disco Newen (2016), Brisa fala à Medium:

Em 2016, fiz meu primeiro disco-solo que se chama "Newen", que significa força em Mapundungun. Então, a identidade indígena sempre existiu dentro de mim. Porque o que sustenta o corpo é a identidade e eu me reconheço como mulher indígena desde criancinha. Principalmente, por tudo que eu vivenciei com a minha família, por tudo que eu conheci, aprendi, por mais que fosse no contexto urbano, o corpo estava gritando ancestralidade. Quando comecei a cantar, já sentia muito esta referência com o canto de músicas andinas, principalmente, as que fazem referência ao povo mapuche, ao povo ameríndio, ao povo araucano. E a ideia do "Newen" era colocar esse idioma para manter a língua do meu povo viva. Depois, mudei as linhas de rap que eu tinha construído e fui construindo o flow (Brisa Flow, Medium, 2019) 
Seu segundo disco, Selvagem como o Vento (2018) conta a história de uma mulher indígena no contexto urbano: "é sobre a sobrevivência da mulher indígena urbana, em sua constante reconstrução de identidade e ancestralidade, apagadas pelo processo de embranquecimento efetuado nos países latino-americanos" (Brisa Flow, Tenho Mais Discos que Amigos, 2019).

\footnotetext{
Quis trazer este ar moderno que o indígeno-futurismo - um movimento decolonialista que usa as transculturalidades embutidas. Trata-se de um movimento que traz essas diferentes culturas dos povos ancestrais para estarem presentes nas nossas vidas sem invisibilizar nenhuma. Esta é a nossa sociedade hoje, a nossa visão de futuro. Nós não estamos presos no passado, mas também não podemos esquecer o que foi a nossa cultura que é sempre invisibilizada (PINHEIRO, 2019).
}

Em 2020 se juntou a um trio de jazz e gravou e Free Abya Yala (2020) com músicas sobre a América Latina Original: "as canções são uma provocação ao histórico da invasão, chamada com engano de descobrimento do Brasil. As letras improvisadas estão carregadas de força para nos fazer refletir sobre o abril indígena” (RANGEL , 2019).

\section{CONSIDERAÇÕES FINAIS}

A arte indígena brasileira é múltipla e diversificada, e os artistas apresentados neste trabalho são apenas alguns representantes musicais deste universo. Discutindo questões contemporâneas, como a vida do indígena na cidade, e questões ancestrais, como crenças, rituais e demarcação de terra, os artistas reafirmam sua existência e resistência neste país plural. Os avanços tecnológicos das últimas décadas têm facilitado cada vez mais o aprendizado, produção e distribuição independente de arte. Os computadores, smartphones e a web 2.0 são ferramentas que tornam possível que o sujeito aprenda sobre os processos musicais, grave sozinho suas composições e faça a distribuição do produto final nas redes sem depender de produtores, gravadoras e estúdios profissionais. Essa é uma mudança que afetou todo o cenário da música, incluindo a arte indígena, permitindo que o trabalho dos artistas independentes tenha um alcance cada vez maior na sociedade. Assim, os artistas indígenas buscam quebrar as barreiras da invisibilidade que foram impostas aos povos indígenas.

Apesar de todos os esforços do Estado e da sociedade brasileira voltados ao apagamento e exclusão dos povos originários ao longo dos séculos, eles resistem. Este trabalho procurou mostrar algumas das formas pelas quais artistas indígenas manifestam essa resistência e marcam suas identidades, culturas e línguas. Com a apropriação das novas tecnologias, os artistas fazem suas vozes e palavras ecoarem ao vento, por toda a internet, buscando verdadeiras transformações sociais necessárias para garantir sua sobrevivência, e a valorização de suas indianidades, que são múltiplas e diversas. Compreender essa diversidade, a existência de muitos modos de ser indígena e em muitos 
contextos diferentes é essencial para a evolução dos debates acerca das questões que permeiam o universo indígena atual.

Os esforços desses artistas não se resumem às suas músicas, mas vão muito além delas. A arte que produzem é reflexo das lutas diárias, das vivências, e das violências a que estão sujeitos em uma sociedade que busca cercear e dificultar suas próprias existências por não se conformarem ou se adequarem ao padrão de sujeito ideal da lógica capitalista. Acredito que essas vozes e discursos indígenas possam contribuir para os debates sobre a condução de planejamentos e políticas linguísticas locais que contemplem a valorização não apenas das línguas indígenas, mas também de seus discursos e suas práticas.

\section{AGRADECIMENTOS}

À Fundação de Amparo à Pesquisa e Inovação do Estado de Santa Catarina (FAPESC) e à Coordenação de Aperfeiçoamento de Pessoal de Nível Superior Brasil (CAPES) pela bolsa de mestrado que possibilitou a realização deste trabalho (edital de chamada pública FAPESC 05/2019).

\section{REFERÊNCIAS}

AMANTE, V. Quem são os pardos no Brasil? A reafirmação identitária da rapper Katú Mirim. Catarinas. 2019a. Disponível em https://catarinas.info/quem-sao-os-pardos-no-brasil-a-reafirmacao-identitaria-da-rapper-katumirim/ Acesso em 15 de nov. de 2020.

AMANTE, V. Rap em Guarani e funk em Kayapó no Yby Festival da Música Indígena. Catarinas. 2019b. Disponível em https://catarinas.info/rrap-em-guarani-e-funk-em-kayapo-no-yby-festival-da-musica-indigena/ Acesso em 28 de nov. de 2020 .

ANDRADE, K. Em sua língua nativa, Nory Kaiapó mostra o funk das aldeias indígenas. Kondzilla. 2019. Disponível em https://kondzilla.com/m/em-sua-lingua-nativa-nory-kaiapo-mostra-o-funk-das-aldeias-indigenas Acesso em 29 de nov. 2020

BARBA, W. Um papo com Oz Guarani, o primeiro grupo de rap indígena de São Paulo. Vice. 2017. Disponível em: https://www.vice.com/pt/article/nzpeqq/oz-guarani-rap-indigena Acesso em 22 de nov. 2020.

BRITO, C. \#Mulher Bacana Lê: Livro busca ensinar sobre a história dos povos indígenas no Brasil. Revista Glamour. 2020 Disponível em https://revistaglamour.globo.com/Lifestyle/Cultura/noticia/2020/10/mulher-bacana-le-livrobusca-ensinar-sobre-historia-dos-povos-indigenas-no-brasil.html Acesso em 26 de nov. 2020.

BRUMATTI, G. Do jornalismo à 'sofrência': conheça a primeira rádio indígena online do Brasil. G1. 2020. Disponível em https://g1.globo.com/sp/campinas-regiao/terra-da-gente/noticia/2020/04/19/do-jornalismo-a-sofrenciaconheca-a-primeira-radio-indigena-online-do-brasil.ghtml Acesso em 28 de nov. de 2020.

DE VOLTA AO PORTO DO BOI. Disponível em: https://pt.portodoboi.com/ Acesso em 19 de nov. 2020.

DEHÓ, M. Banda de Brasília faz metal em tupi para chamar atenção à causa indígena. UOL. 2014. Disponível em: https://musica.vol.com.br/noticias/redacao/2014/10/14/banda-de-brasilia-faz-metal-em-tupi-para-chamaratencao-a-causa-indigena.htm?cmpid=copiaecola Acesso em 01 de nov. 2020. 
DI GIACOMO, F. Futurismo Indígena. UOL. 2020. Disponível em: https://www.uol.com.br/ecoa/reportagensespeciais/kunumi-mc-quer-quebrar-estereotipos-e-mostrar-como-tecnologias-indigenas-sao-avancadas/ Acesso em 21 de nov. 2020.

DJUENA TIKUNA. Disponível em https://djuenatikuna.com Acesso em 28 de nov. 2020.

FERNANDES, L. S. Oz Guarani. Poética de resistência política. 2018. Trabalho de Conclusão de Curso. Departamento de Ciências Sociais. Universidade Federal de São Paulo, Guarulhos, 2018.

FONSECA, D. Novos militantes indígenas. Revista TRIP. 2020. Disponível em

https://revistatrip.uol.com.br/trip/novos-militantes-indigenas Acesso em 26 de nov. 2020.

GARGIONI, A.A.D.P. A performatização de identidades por vlogueiros indígenas no youtube. 2019. Tese (Doutorado em Linguística). Programa de Pós-Graduação em Linguística Aplicada, Instituto de Estudos da Linguagem, Universidade Estadual de Campinas, Campinas, 2019.

Guarani-Kaiowá nas quebradas: conheça os Brô MCs, pioneiros do rap indígena do Brasil. Reverb. 2019. Disponível em: https://reverb.com.br/artigo/guarani-kaiowa-nas-quebradas-conheca-os-bro-mcs-pioneiros-do-rap-indigenado-brasil Acesso em 05 de nov. 2020

GUEROLA, C. A demarcação de terras indígenas como política linguística. Revista Da ABRALIN, 17(2), 2019. Disponível em: http://revista.abralin.org/index.php/abralin/article/view/512

GUIDON, N. As ocupações pré-históricas do Brasil (excetuando a Amazônia). In História dos Índios do Brasil. CUNHA, M.C. (org). São Paulo: Companhia das Letras: Secretaria Municipal de Cultura: FAPESP: 1992. p. 37-52. Disponível em: http://etnolinguistica.wdfiles.com/local--files/hist\%3Ap37-52/p37-52_Guidon_As_ocupacoes_prehistoricas_do_Brasil.pdf

IBGE Indigenas. Disponível em: https://indigenas.ibge.gov.br/ Acesso em 24 de nov. 2020.

LIMA, T. \#ÍndioNãoÉFantasia: quem é a indígena que iniciou debate sobre o uso de fantasias. G1. 2018 Disponível em https://g1.globo.com/carnaval/2018/noticia/indionaoefantasia-quem-e-a-indigena-que-iniciou-debate-sobre-usode-fantasias.ghtml Acesso em 15 de nov. de 2020

MAHER, T. M. Políticas Linguísticas e Políticas de Identidade: currículo e representações de professores indígenas na Amazônia Ocidental brasileira. Currículo sem Fronteiras, v. 10, p. 33-48, 2010. Disponível em: http://www.curriculosemfronteiras.org/vol10isslarticles/maher.pdf

MAHER, T. M. Do étnico ao pan-étnico: negociando e performatizando identidades indígenas. D.E.L.T.A., 32.3, p. 719733, 2016a.

MAHER, T.M. Sendo índio na cidade: mobilidade, repertório linguístico e tecnologias. Revista da Anpoll, n. 40, p. 5869, Florianópolis, jan./jun. 2016b.

MARI, J. de. Rap indígena sai da aldeia e protesta: "Agro não é tech nem pop. Ele mata". TAB UOL. 2019. Disponível em: https://tab.uol.com.br/noticias/redacao/2019/12/03/rap-indigena-cresce-no-pais-e-protesta-agro-nao-e-technem-pop-ele-mata.htm Acesso em 03 de nov de 2020.

MARTINS, A. M. S.; KNAPP, C.; SALES, A. Políticas linguísticas na Licenciatura Intercultural Indígena - Teko Arandu. ReVEL, v. 14, n. 26, 2016. http://www.revel.inf.br/files/46428b07a66d4e8d191039e53d285737.pdf

MARTINS, B. Katú Mirim, rapper paulista, é sinônimo de resistência indígena na cidade. Reverb. 2019 Disponível em https://reverb.com.br/artigo/katu-mirim-rapper-paulista-e-sinonimo-de-resistencia-indigena-na-cidade Acesso em 15 de nov. de 2020

MINDÊLO, O. Brô MCs. Continente. 2018. Disponível em: https://www.revistacontinente.com.br/edicoes/211/bro-mcs1 Acesso em 05 de nov de 2020

MIRANDA, B. "The way I am is an outrage": the Indigenous Brazilian musicians taking back a burning country. 2020. The Guardian. Disponível em: https://www.theguardian.com/music/2020/oct/26/brazil-music-indigenous-tribesenvironment-bolsonaro Acesso em 18 de nov. 2020

MIRIM, W. J. Werá Jeguaka Mirim, o rapper Kunumi MC - quando a pessoa se torna ativista. In. Revista Tuíra. n.1, p.112-114, jan. 2019, Escola de Ativismo. Disponível em https://escoladeativismo.org.br/wpcontent/uploads/2019/02/Tuira01_WEB.pdf Acesso em 28 de nov. 2020. 
MONTESANI, B. Quem são os Brô MC's, primeiro grupo de rap indígena do Brasil. Nexo Jornal. 2017. Disponível em: https://www.nexojornal.com.br/expresso/2017/02/16/Quem-s\%C3\%A3o-os-Br\%C3\%B4-MCs-primeiro-grupo-de-rapind\%C3\%ADgena-do-Brasil Acesso em 08 de nov. 2020

MORAIS, H. Ruynas, novo disco da Andróide Sem Par, pasa pelo redescobrimento indígena de Juão Nun e vai além. O inimigo - Medium. 2019. Disponível em https://medium.com/o-inimigo/ruynas-novo-disco-da-andr\%C3\%B3idesem-par-passar-pelo-redescobrimento-ind\%C3\%ADgena-de-ju\%C3\%A3o-nin-e-vai-al\%C3\%A9m-75b44bb25dce Acesso em 28 de nov. de 2020.

MORO, G. H. Zândhio Huku: entrevista com o vocalista e criador do Arandu Arakuaa. Whiplash. 2020. Disponível em: https://whiplash.net/materias/news_739/324882-aranduarakuaa.html Acesso em 30 de out. 2020.

MOTT, L. A inquisição no Maranhão. Semana de História da Universidade Federal do Maranhão. 1993. Disponível em http://snh2017.anpuh.org/resources/download/1245522207_ARQUIVO_luizmott.pdf

MUNDURUKU, D. As literaturas indígenas e as novas tecnologias da memória. In: DELGADO, P. S.; JESUS, N. T. (Orgs.) Povos indígenas no Brasil: perspectiva no fortalecimento de lutas e combate ao preconceito por meio do audiovisual. Curitiba: Brazil Publishing, 2018, p. 169-180.

OLIVEIRA, L. Bro MC's Rap Indígena: O pop e a constituição de fóruns cosmopolíticos na luta pela terra Guarani e Kaiowa. Revista Eco Pós, vol. 19, n. 3, p.199-220, Rio de Janeiro, 2016.

PAGLIARO, H. AZEVEDO, M.M. SANTOS, R.V. Demografia dos Povos Indígenas no Brasil: um panorama crítico. In Demografia dos Povos Indígenas no Brasil. PAGLIARO, H. AZEVEDO, M.M., SANTOS, R.V. (orgs.). Rio de Janeiro: Editora FIOCRUZ. p. 11-32, 2005

PINHEIRO, J. Brisa Flow defende a demarcação de terras indígenas em "Fique Viva". Tenho Mais Discos que Amigos. 2019. Disponível em https://www.tenhomaisdiscosqueamigos.com/2019/07/19/brisa-flow-indigena-fique-viva/ Acesso em 29 de nov. 2019.

RÁDIO YANDÉ. Disponível em: https://radioyande.com/ Acesso em: 30 de out. 2020.

RANGEL, C. Poesia-Improviso de Brisa Flow invoca ancestralidade com jazz em "Free Abya Yala". Hits Perdidos. 2020. Disponivel em https://hitsperdidos.com/2020/05/20/brisa-flow-free-abya-yala/ Acesso em 30 de nov. 2020.

RIBEIRO, K. Djuena Tikuna: cantora indígena usa música em prol da preservação e resistência de seu povo. 2019. Disponível em https://reverb.com.br/artigo/djuena-tikuna-cantora-indigena-usa-musica-em-prol-da-preservacaoe-resistencia-de-seu-povo Acesso em 28 de nov. de 2020.

RODRIGUES, A. D. Línguas Indígenas: 500 anos de descobertas e perdas. D EL.TA, vol 9, n. 1, p. 83-103, 1993. SÃO PAULO. Justiça Federal da $3^{a}$ Região. Tutela Cautelar Antecedente (12134) n 5002056-31.2020.4.03.6100. São Paulo, 07 de abril 2020. Disponível em: https://ponte.org/wp-content/uploads/2020/05/Decis\%C3\%A3o.06.04.pdf Acesso em 20 de nov. 2020.

SEVERO, C. G. Das línguas indígenas: por um olhar decolonial em políticas linguísticas. Revista Digital De Políticas Linguísticas, v. 11, p. 143-158, 2019a. Disponível em: https://revistas.unc.edu.ar/index.php/RDPL/article/view/26740 SEVERO, C. G. A Biopolítica da língua no Brasil: eugenia, mestiçagem e racismo. In: BUTTURI JUNIOR, A; CANDIOTTO, C; SOUZA, P. de; CAPONI, S. (org.). Foucault \& as práticas de liberdade 1: o vivo \& seus limites. Campinas, SP: Pontes Editores, 2019b.

SOUZA, F. A banda que toca heavy metal em tupi-guarani. BBC Brasil. 2016. Disponível em: https://www.bbc.com/portuguese/brasil-37593361 Acesso em 05 de nov. 2020.

STEVAUX, D. Brisa Flow: "O que sustenta o corpo é a identidade. Me reconheço como mulher indígena desde criancinha". Medium. 2019 Disponível em https://medium.com/mecalovemeca/brisa-flow-o-que-sustenta-o-corpo\%C3\%A9-a-identidade-812aac5fc48b Acesso em 29 de nov. 2020.

VIEIRA, B. M. Indígenas da Zona Norte de SP cantam rap em guarani para defender causa indígena. G1 SP. 2019 Disponível em: https://g1.globo.com/sp/sao-paulo/noticia/2019/01/24/jovens-indios-da-zona-norte-de-sp-cantamrap-em-tupi-guarani-para-defender-causa-indigena.ghtml Acesso em 04/novembro/2020.

VASCONCELOS, C; SILVA, S. Em guarani, WERA MC usa o hip hop para cantar a luta e resistência indígena. Ponte Jornalismo. 2020. Disponível em https://ponte.org/em-guarani-wera-mc-usa-o-hip-hop-para-cantar-a-luta-eresistencia-indigena Acesso em 05 de nov de 2020 